DOI: $10.14451 / 2.150 .72$

\title{
ИЗМЕНЕНИЕ И РАСТОРЖЕНИЕ ДОГОВОРОВ В СВЯЗИ С СУЩЕСТВЕННЫМ ИЗМЕНЕНИЕМ ОБСТОЯТЕЛЬСТВ В СООТВЕТСТВИИ С ПРАВИЛАМИ, СОДЕРЖАЩИМИСЯ В УНИФИКАЦИОННЫХ АКТАХ
}

\author{
(C) 2020 Понька Виктор Федорович \\ доктор юридических наук, начальник Управления правового обеспечения деятельности \\ Российская Академия Наук, Россия, Москва \\ E-mail: Ponka@pran.ru \\ (c) 2020 Посохов Сергей Петрович \\ кандидат юридических наук, \\ заместитель начальника Управления правового обеспечения деятельности \\ Российская Академия Наук, Россия, Москва \\ E-mail: SPPosokhov@presidium.ras.ru
}

В настоящей статье исследуются особенности изменения и расторжения договора в связи с существенно изменившимися обстоятельствами в соответствии с правилами, содержащимися в унификационных актах на примере Principles of European Contract Law (PECL), Unidroit Principles of International Commercial Contracts, Definitions and Model Rules of European Private Law, Draft Common Frame of Reference (DCFR) и European Contract Code.

Ключевые слова: договор, ответственность, изменение договора, расторжение договора, невозможность исполнения, убытки, существенное изменение обстоятельств.

a) Principles of European Contract Law (PECL).

Статья 6:111 Принципов европейского договорного права достаточно скрупулезно описывает процедуру расторжения и изменения договора в связи с существенно изменившимися обстоятельствами.

Согласно п.2 указанной статьи, «если исполнение контракта становится чрезмерно обременительным из-за изменения обстоятельств, стороны обязаны начать переговоры с целью изменения контракта или прекращения его» [1].

Указанная статья Принципов европейского договорного права указывает на ряд признаков, которые характеризуют обременительность описанных выше обстоятельств.

Во-первых, возникшие обстоятельства имели место быть после заключения договора.

Во-вторых, обстоятельства носили объективно-обусловленный характер и не могли быть приняты в расчет стороной при заключении договора.

В-третьих, риск изменения обстоятельств не является таковым, чтобы в соответствии с договором сторона должна была бы нести его.

Юридическая техника Принципов европейского договорного права находится на достаточно высоком уровне. На ее высокий уровень указывает сочетание двух основополагающих принципов в одной статье - pacta sunt servanda и clausula rebus sic stantibus.

При этом, принцип pacta sunt servanda, закрепленный в п. 1 ст. 6:111 Принципов европейского договорного прав, предусматривает ряд обстоятельств, при которых исполнение обязательства представляется чрезвычайно обременительным, в частности, это может быть связано с ростом цен, либо потерей стороной интереса во время исполнения договора.

Кроме этого, важно отметить, что положения Принципов европейского договорного права достаточно внятно дают понять как судья может изменить договор, устанавливая для этого определенные границы.

Вслед за Венской конвенцией 1980 года «О международной купле-продажи товаров» в Принципах европейского договорного права также предусмотрена возможность взыскать убытки, которые возникли в имущественной сфере пострадавшей стороны.

Согласно п.3 ст. 6:111 Принципов европейского договорного права, «если стороны не достигли соглашения в течение разумного периода времени, то суд может:

(a) расторгнуть договор с момента, способом и на условиях, которые будут судом; или

(b) изменить договор, обеспечив соблюдение баланса интересов между сторонами, соблюдая 
обоснованность и справедливость распределения при распределении прибыли и расходов» [2].

Стоит отметить, что суд может присудить возмещение убытков недобросовестной стороне, которая, например, сорвала проведение переговоров или вовсе отказалась от их проведения.

Механизм прекращения договора, предусмотрен в третьем разделе Принципов европейского договорного права.

Так же как и в Венской конвенцией 1980 «О международной купле-продажи товаров» в соответствии со ст.9:301 Принципов европейского договорного права установлено, что сторона вправе расторгнуть договор, при условии надлежащего извещения другой стороны договора.

При этом, стоит обратить внимание на то, что сторона может утратить свое право на расторжении договора, если не предпримет действий по направлению в разумный срок извещения о расторжении договора другой стороне, после того как другая сторона узнала о неисполнении договора.

В соответствии со ст. 9:305 Принципов европейского договорного права расторжение договора исключает возможность дальнейшего исполнения сторонами обязательства. Однако, если сторона договора не исполнила обязательства либо исполнила их ненадлежащим образом при расторжении договора в связи с существенно изменившимися обстоятельствами это не освобождают виновную сторону от неблагоприятных имущественных последствий в виде возмещения убытков.

Сторона, инициирующая расторжение договора, может вернуть имущество, полученное по договору, другой стороне, если это оказалось для стороны, возвращающей имущество, невыгодным, например, из-за потери стоимости такого имущества в связи с неисполнением другой стороной.

После расторжения договора сторона вправе требовать встречное предоставление в виде денег, уплаченных ею за не осуществленное в отношении нее исполнение.

Согласно ст. 9:309 Принципов европейского договорного права после расторжения договора «сторона, которая произвела надлежащее исполнение, которое не представляется возможным вернуть и за которое не были получены денежные средства, может выплатить другой стороне разумную компенсацию за исполнение» [3].

\section{b) Unidroit Principles of International} Commercial Contracts.

Аналогичные положения о существенно изменившихся обстоятельствах содержатся и в ст. 6.2.1-6.2.3 Принципов международных коммерческих договоров УНИДРУА 2010 г. [4], и в ст. III-1:110 Модельных правил европейского частного права 2009 [5] г.

Принципы международных коммерческих договоров УНИДРУА играют важнейшую роль в сфере правового регулирований отношений коммерческого оборота. Больше того, их значение настолько велико, что за ними закрепилась роль источника права, когда стороны договора решают подчинить свои отношения данному унификационному акту.

Так, согласно статье 6.2.1 Принципов международных коммерческих договоров в случае, «если исполнение договора для стороны становится затруднительным, то данная сторона обязуется исполнить свои обязательства с учетом особенностей положения статьи о затруднениях исполнения» [6].

Не смотря на принцип обязательного исполнения договора как одного из фундаментальных во внешнеторговом обороте, его абсолютный характер может быть нивелирован различными как юридической, так и экономической целесообразности для стороны. Когда возникают обстоятельства, которые могут привести к нарушению равновесия и имущественной эквивалентности сторон, Принципы международных коммерческих договоров облекают такие обстоятельства в исключительный случай, придавая им характер так называемого затруднения, именуемого «hardship».

Само по себе понятие «затруднение исполнения» известно и Венской конвенции «О международной купле-продаже товаров». Юридическое понятие затруднения идентично используемым в национальных правовых режимах таким категориям как «тщетность договора», «отпадение основания сделки», «существенно изменившиеся обстоятельства, «clausula rebus sic stantibus» и тд.

Как уже ранее отмечалось, термин «hardship» или «hardship clauses» международной практикой был выбран не случайно, поскольку каждая из указанных выше доктрин, обусловлена своеобразием своей национальной системой права, тогда как в международной торговой практике необходимо использовать механизмы, отра- 
жающие указанные концепции в очень мягкой форме, поэтому используется так называемые «широкие термины», носящие обобщающий характер.

Согласно ст. 6.2.3. Принципов международных коммерческих договоров под затруднениями следует понимать обстоятельства, которые нарушают равновесие в договорных отношениях путем существенного осуществления затрат одной из стороной для исполнения договора. Больше того, затруднение может быть также обусловлено не получением либо уменьшением получения того социально-экономического эффект, на который стороны рассчитывали, заключая договор [7].

Для того, чтобы затруднение приобрело для сторон юридическое значение, оно должно соответствовать следующим признакам:

во-первых, обстоятельство, приводящее к затруднению, может возникнуть только после заключения договора, а в момент заключения такого договора сторона не могла его предвидеть;

во-вторых, указанные обстоятельства в силу невозможности их предвидеть не учтены стороной договора;

в-третьих, стороны не могут повлиять на такие события, они происходят вне их воли и являются не зависимыми от желания сторон;

в-четвертых, сторона в силу указанных причин не может принять на себя риск возникновения данных обстоятельств.

Итак, рассмотрим критерии определения затруднений.

Нарушение баланса интересов сторон договора или существенное изменение равновесия может проявляться в нескольких способах:

а. Увеличение стоимости исполнения.

Указанный способ характеризуется существенным возрастанием расходов одной стороны для осуществления ею исполнения обязательств по договору. На увеличение стоимости договора могут влиять различные факторы, а зачастую их совокупность, что может выражаться повышении стоимости на энергоносители, повышении стоимости на нефть, газ, изменение стоимости иностранной валюты, повышении пошлин на товар, принятие нормативного правового акта, ужесточении таможенного режима, отмены налоговых льгот и пр.

b. Уменьшение ценности исполнения, получаемого стороной.
Данный способ затруднений обусловлен снижением ценности получения от заключенного договора какого-либо блага, на которое рассчитывала сторона при его заключении. Или же вовсе не получение чего-либо по договору. На существенное уменьшение ценности могут влиять те же самые причины, что и на повышение стоимости исполнения. Возникшие обстоятельства могут быть результатом серьезных изменений в рыночной ситуации и тд.

Согласно ст. 6.2.3. Принципов международных коммерческих договоров в случае затруднений потерпевшей стороне предоставлено право, согласно которому она вправе инициировать процесс внесения изменений в договор.

При недостижении сторонами договора соглашения в разумный срок любая сторона может обратиться в суд.

При квалификации судом обстоятельств в качестве затруднений, суд вправе либо расторгнуть договор либо изменить договор, мотивируя свою позицию необходимостью соблюдения баланса интересов сторон заключенного договоpa.

Следует обратить внимание на то, что пункт 1 ст.6.2.3. Принципов международных коммерческих договоров устанавливает обязанность стороны указать основание предложения изменить условия договора в связи с возникшими затруднениями. При этом, предложение изменить договор должно быть обоснованным и ссылаться на факт произошедшего затруднения. Отсутствие мотивов и оснований в предложении об изменении договора, делают его юридически недостижимым, те не приводящей к каким-либо последствиям.

Важно отметить, что само по себе предложение об изменении договора не является основанием для приостановки исполнения договора, поскольку, в противном случае, недобросовестная сторона может злоупотребить своим положением. Приостановка исполнения может иметь место быть только в исключительных случаях.

Весьма показательным в этом плане выступает иллюстрация в комментарии Принципов международных коммерческих договоров, сделанная А.С.Комаровым: «А заключает договор с В о строительстве завода. Завод должен быть построен в стране X, в которой вводятся новые правила безопасности после заключения договора. Новые правила требуют дополнительного оборудования и поэтому существенно изменяют 
равновесие договора, делая исполнение со стороны А существенно более обременительным. А имеет право просить о пересмотре условий договора и может приостановить свое исполнение, принимая во внимание время, которое необходимо для применения новых правил безопасности, однако А может также приостановить поставку дополнительного оборудования до тех пор, пока не согласована соответствующая адаптация цены» [9].

Предложение стороны об изменении условий договора, а также проведение в этой связи переговоров должны подчиняться принципу добросовестности, предусмотренному в ст. 1.7 Принципов коммерческих договоров, т.е. сторона обязана действовать в соответствии с принятыми в практике международной торговли добросовестностью и честной деловой практикой.*

Если стороны не смогли достигнуть соглашения об изменении договора в связи с обстоятельствами, затрудняющими исполнение, в течение разумного периода времени, то у сторон возникает право обратиться в суд. При этом критерий разумности срока зависит от различного рода обстоятельств, включая сам случай, который привел к затруднению исполнения.

Суд, рассматривающий дело о затруднении исполнения договора, может вынести одно из следующих решений:

Первое - о расторжении договора и прекращении отношений между сторонами. Принципы международных коммерческих договоров предусматривают, что моментом расторжения договора будет считаться дата, указанная самим судом. При этом, помимо этого, Принципы международных коммерческих договоров обязывают суд определить условия, на которых будет происходить расторжение договора (ст. 7.3.1.).

Вторая возможность - изменение условий договора, т.е. их адаптация к изменившимся обстоятельствам. В рамках принимаемого судом решения важное значение имеет справедливое распределение имущественных рисков между сторонами, обусловленными возникновением обстоятельств, приведших к затруднению исполнения. При этом, важно справедливо распределить не только потери, но и полученное по договору.

Однако существует еще одно условие без которого изменение либо расторжение договора будет тщетным - это критерий разумности.

Так, согласно ст.7.1.4 Принципов коммерческих договоров «суд может прекратить или адаптировать договор только тогда, когда это разумно» [10]. При этом следует отметить, что подход к определению разумности тот же, что и в Принципах европейского договорного права.

\section{c) Draft Common Frame of Reference.}

Одноименных подходов к определению понятия «затруднение» придерживаются также Draft Common Frame of Reference, согласно ст.3:1104 которых «должник не отвечает за неисполнение обязанности, если оно вызвано препятствием, находящимся вне сферы контроля должника, и от должника нельзя было разумно ожидать, что он избежит или преодолеет такое препятствие или его последствия» [11].

Модельные правила европейского частного права также и предшествующие унификационные акты устанавливают положение, согласно которому, должник не может быть освобожден от ответственности, обусловленной неисполнением или ненадлежащим исполнением, если возникают основания полагать, что должник разумно ожидал возникновение препятствий в момент заключения договора.

Стоит отметить, что препятствие может носить не только непреодолимый характер, но и временный.

Так, если срок действия препятствия обусловлен периодом времени, должник освобождается от исполнения на период действия такого препятствия. Однако, если в период действия такого препятствия возникнут основать для существенного нарушения, то договор может быть расторгнут и при временных обстоятельствах.

Если препятствие, освобождающее должника от исполнения, носит постоянный характер, договор подлежит расторжению и обязательства прекращаются с учетом особенностей обеспечения принципа имущественной эквивалентности. При этом, речь идет о прекращении взаимных обязанностей по договору.

Что касается последствий расторжения договора ввиду существенно изменившихся обстоятельств, то они регулируются положениями правил о возврате полученного по договору.

Так же, как и в ранее описанных унификационных актах, Модельные правила европейского частного права устанавливают обязанность

\footnotetext{
* Принципы международных коммерческих договоров УНИДРУА 2010. Указанное сочинение//СПС «Консультант Плюс».
} 
должника отправить в разумный срок уведомление кредитору о возникшем препятствии, затрудняющем исполнение договора с момента, когда такие обстоятельства возникли. Несоблюдение данного правила, является основанием для кредитора требовать возмещения убытков в связи с несвоевременным получением такого уведомления.

\section{d) European Contract Code}

Также хотелось бы остановиться еще на одном унификационном акте - Кодексе европейского договорного права.

В соответствии со ст. 97 Кодекса европейского договорного права, «если должник задерживает надлежащее исполнение обязательства или производит его только частично, то названное обязательство нельзя рассматривать как неисполнение, при условии, что ранее произошли непредвиденные чрезвычайные события, которые сделали исполнение чрезмерно должник обязан направить кредитору уведомление о своем намерении воспользоваться этим правом до истечения срока, установленного для исполнения, или до того момента, пока кредитор не обратился к должнику с помощью уведомления» [12].

Из указанной статьи вытекает правило, согласно которому обязательство не может быть квалифицировано неисполненным, если на него оказали воздействия обстоятельства чрезвычайного характера, которое возникло после заключения договора. Однако из данного правила существует и исключение, в соответствии с которым стороны могут предусмотреть в договоре условие о так называемых гарантия исполнения, при которых невозможность исполнения будет квалифицироваться как обстоятельство, приводящее к компенсации кредитора.

Итак, согласно исследуемой статье Кодекса европейского договорного права можно сделать вывод о том, что существенно изменившимися обстоятельствами или затруднениями следует считать такой случай, который приводит к нарушению равновесия между сторонами договорных отношений в силу возрастания издержек либо умаления полученного по договору стороной исполнения.

На основании указанной статьи можно сконструировать следующие признаки:

во-первых, события возникли после заключения договора;

во-вторых, эти события не могли быть раз- умно предвидены стороной при заключении договора;

в-третьих, данные события субъективно не связаны с потерпевшей стороной, т.е. она не может оказывать на них влияние;

в-четвертых, потерпевшая сторона не приняла на себя риск возникновения этих событий.

Согласно Кодексу европейского договорного права возникновение обстоятельств, имеющих существенное значение, дает возможность либо адаптировать под такие условия договор либо его расторгнуть.

Так, реализация права на изменение договора возникает при условии, что обстоятельств, имеющие существенное значение носят временный характер. Правовые последствия реализации такого права связаны с задержкой должником исполнения обязательств по договору на период действия таких обстоятельств либо частичным исполнением, которые в данном случае не будут рассматриваться как отказ либо частичный отказ от исполнения обязательства.

Возникновение таких обстоятельств обязывает должника незамедлительно уведомить кредитора, сообщив в мотивированном уведомлении о приостановке исполнения по договор, ссылаясь на существенно изменившиеся обстоятельства.

В заключении главы настоящего исследования, автору представляется возможным сделать определенные выводы.

Во-первых, исследуя изменение и расторжение договоров в связи с существенно изменившимися обстоятельствами в национальной системе права, автором было проанализировано три основных договора - оказание туристических услуг, купля-продажа и аренда, на основании которых производилось моделирование поставленной рамками данного параграфа проблемы.

Среди указанных договоров особое место занимает договор об оказании туристических услуг. Обусловлено этом двумя факторами. С одной стороны, тем, что туристическая деятельность носит рисковый характер. С другой стороны, выбор исследования данного договора связан с наличием Федерального закона РФ «Об основах туристской деятельности в Российской Федерации», который среди прочих нормативных правовых актов является своего рода уникальным законом. Уникальность закона применительно к настоящему исследования за- 
ключается в том, что закон не только предусматривает возможность изменения и расторжения договора в связи с существенным изменением обстоятельств, но и определяет критерии, в соответствии с которым турист получает такую возможность. Среди таких критериев ст. 10 названного закона устанавливает: «ухудшение условий путешествия; изменение сроков совершения путешествия; непредвиденный рост транспортных тарифов; невозможность совершения туристом поездки по независящим от него обстоятельствам (болезнь туриста, отказ в выдаче визы и другие обстоятельства)» [13].

Исследование изменения и расторжения договоров купли-продажи и аренды было предопределено наибольшей распространённостью данных договоров в гражданско-правовом обороте.

Договоры купли-продажи и аренды - одни из самых распространенных гражданскоправовых договоров, значение которых переоценить невозможно. Та юридическая глубина, которую несут в себе эти договоры обусловлены преимущественным среди прочих договоров охватом регулирования им отношений.

Однако в отличие от ранее описанного договора об оказании туристских услуг, расторжение или изменение договора купли-продажи и аренды в связи с существенно-изменившимися обстоятельствами подчиняются общими требованиям Гражданского кодекса РФ, предусмотренным ст.451 Гражданского кодекса Российской Федерации.

Во-вторых, в рамках исследования изменения и расторжения договора международной купли-продажи товаров в связи с существенным изменением обстоятельств, автором отмечено, что в отличие от национальной системы права Конвенция ООН «О международной купле-продаже товаров» 1980 г., регламентируя вопросы изменения и расторжения договора не описывает детально условия наступления существенно изменившихся обстоятельств, а допускает для заинтересованной стороны возможность, создающую основание для освобождения от ответственности. При этом, используемым Конвенцией термином является «препятствий исполнения».

Положения Конвенции «О международной купле-продаже товаров» построены на компромиссе, ориентированном на отражение общенациональных интересов стран - участниц такой конвенции. Поэтому подходы к существенно изменившимся обстоятельствам в Конвенции отражают различные аспекты и зачастую приводят к смешению четко различаемых в национальных системах права институтов: обстоятельства, имеющие существенное значение, непреодолимая сила, невозможность исполнения. Все это продиктовано наличием прагматических причин - создать условия, при которых у заинтересованной стороны появится возможность освободится от обязательств при возникновении обременяющих обстоятельств. Поэтому теоретизация такого понятия как clausula rebus sic stantibus здесь выглядела бы искусственно излишним.

Для того, чтобы обстоятельство относилось к понятию «препятствие», оно должно обладать определенными признаками:

а) возникновение указанного обстоятельства не может быть предвидимым стороной международного договора. Это означает, что стороны в момент заключения договора не могут разумно предвидеть, что произойдет обстоятельство, которое затруднит или сделает невозможным исполнение контракта;

b) обстоятельство должно обладать неотвратимым характером. Суть данного признака заключается в том, что лицо, не исполнившее обязательства из международного контракта, должен доказать, что оно предприняло все необходимые меры по предотвращению такого обстоятельства, но в силу его объективной природы не смог.

В третьих, исследуемые унификационные акты договорного права - Principles of European Contract Law (PECL), Unidroit Principles of International Commercial Contracts, Definitions and Model Rules of European Private Law: Draft Common Frame of Reference (DCFR) и European Contract Code исходят из совпадающих подходов к определению существенного изменения обстоятельств, основанию и условиям расторжения (изменения) договора, включая правовые последствия.

В след за Конвенцией «О международной купле-продаже товаров» унификационные акты также используют собирательное понятие «hardship», обозначающее препятствие исполнению договора.

Юридическое понятие затруднения идентично используемым в национальных правовых системах права таким категориям как «тщет- 
ность договора», «отпадение основания сделки», «существенно изменившиеся обстоятельства, «clausula rebus sic stantibus» и тд.

Термин «hardship» международной практикой был выбран не случайно, поскольку каждая из указанных выше доктрин, обусловлена своеобразием своей национальной системы права, тогда как в международной торговой практике необходимо использовать механизмы, отражающие указанные концепции в очень мягкой форме, поэтому используется термины, охватывающие широкий смысл.

В соответствии с унификационными актами под затруднениями следует понимать обстоятельства, которые нарушают равновесие в договорных отношениях в связи с возникновением существенных затрат у одной из сторон, производимых для исполнения договора. Больше того, затруднение может также быть связано с не получением либо уменьшением получения того социально-экономического эффект, на который стороны рассчитывали, заключая договор.

Для того, чтобы затруднение приобрело для сторон юридическое значение, оно должно соответствовать следующим признакам:

а) обстоятельство, приводящее к затруднению, должно возникнуть только после заключения договора;

b) стороны в момент заключения договора не могли предвидеть данное обстоятельство;

c) стороны не могут повлиять на такие события, они происходят вне их воли и являются не зависящими от желания сторон;

d) сторона в силу указанных причин не может принять на себя риск возникновения данных обстоятельств.

\section{Библиографический список}

1. Рамберг Я. Международные коммерческие транзакции / пер. с англ. под ред. Н.Г. Вилковой. 4-е изд. М.: «Инфотропик Медиа», 2011. 896 с. // СПС «Консультант Плюс».

2. Рамберг Я. Международные коммерческие транзакции. Указанное сочинение // СПС «Консультант Плюс».

3. Рамберг Я. Международные коммерческие транзакции. Указанное сочинение // СПС «Консультант Плюс».

4. Принципы международных коммерческих договоров УНИДРУА, 2010 г. (пер. с англ. А.С. Комарова) «Статут», 2013 // СПС «Консультант Плюс».

5. Модельные правила европейского частного права: Пер. с англ. / Науч. ред. Н. Ю. Рассказова. М.: «Статут», 2013 // СПС «Консультант Плюс».

6. Принципы международных коммерческих договоров УНИДРУА, 2010 г. Указанное сочинение//СПС «Консультант Плюс».

7. Принципы международных коммерческих договоров УНИДРУА, 2010 г. Указанное сочинение//СПС «Консультант Плюс».

8. Принципы международных коммерческих договоров УНИДРУА 2010» (пер. с англ. А. С. Комарова) «Статут», 2013 // «СПС Консультант плюс».

9. Принципы международных коммерческих договоров УНИДРУА 2010. Указанное сочинение//СПС «Консультант Плюс».

10. Принципы международных коммерческих договоров УНИДРУА 2010. Указанное сочинение//СПС «Консультант Плюс».

11. Модельные правила европейского частного права (перевод с английского) (науч. ред. Н. Ю.Рассказова) «Статут», 2013 // СПС «Консультант Плюс».

12. Кодекс европейского договорного права - European Contract Code: общий и сравнительно-правовой комментарий (книга 1), Белов В. А., «Юрайт», 2015// СПС «Консультант Плюс».

13. Федеральный закон «Об основах туристской деятельности в Российской Федерации» от 24.11.1996 N 132Ф3 // «Собрание законодательства РФ», 02.12.1996, N 49, ст. 5491. 